\title{
Shinyei Based Sensor with Added Roof Enhanced Detection of Indoor Particulate Matter
}

\author{
Nur Atiqah Surib ${ }^{1}$, M A Fatihah $^{1}$, J NorRuwaida ${ }^{1}$, M Rashid ${ }^{1}, \mathbf{M}$ \\ Khairunnisa $^{1, *}$, I Wuled Lenggoro ${ }^{2,3}$
}

${ }^{1}$ Malaysia-Japan International Institute of Technology,

Universiti Teknologi Malaysia, 54100, Kuala Lumpur, MALAYSIA

${ }^{2}$ Graduate School of Bio-Applications and Systems Engineering,

Tokyo University of Agriculture and Technology, Koganei, Tokyo 184-8588, JAPAN

${ }^{3}$ Department of Chemical Engineering,

Tokyo University of Agriculture and Technology, Koganei, Tokyo 184-8588, JAPAN

*Corresponding Author

DOI: https://doi.org/10.30880/ijie.2019.11.07.009

Received 30 May 2019; Accepted 30 July 2019; Available online 10 August 2019

\begin{abstract}
Commercially available monitoring systems in the market are expensive and rather challenging to maintain, had prompted researchers to invent low-cost monitoring system as alternative. New cost-effective, portable and user-friendly prototypes have been proposed using Shinyei PPD42NS sensor for PM 10 monitoring. The performances of the original and roofed prototype were tested by measuring indoor $\mathrm{PM}_{10}$ concentrations. The roofed prototype showed a higher reading of $\mathrm{PM}_{10}\left(822 \mu \mathrm{gm}^{-3}\right)$ detected at minutes 16 compared to the original prototype $\left(0 \mathrm{\mu gm}^{-3}\right)$ due to the presence of a roof decreased the velocity of particulate matter and accumulate before entered the Shinyei sensor inlet. CFD analysis of the roofed prototype illustrated lower air velocity of 0.3 $\mathrm{ms}^{-1}$ compared to original prototype having a velocity of $0.4 \mathrm{~ms}^{-1}$. The original prototype exhibit comparable performance to the reference instrument (GRIMM) in detecting PM $_{10}$ concentration. Shinyei PPD42NS inside the original prototype showed high sensitivity by detecting higher concentration of $\mathrm{PM}_{10}$ with readings of $79 \mu \mathrm{gm}^{-3}$. The prototypes were successfully developed by detecting the presence of $\mathrm{PM}_{10}$ and addition of roof showed increase efficiency in detecting particulate matter in the air.
\end{abstract}

Keywords: Arduino, air quality, air flow, computational fluid dynamics, $\mathrm{PM}_{10}$

\section{Introduction}

Recently, the problem of air pollution due to the rapid growth of urbanisation and industrialisation has attracted much attention because of the possible adverse various health effects on humans, as well as damage caused to the ecosystem, buildings and of course reduced visibility. The Air Pollution Index (API) was introduced to provide a comprehensive source of information regarding the level of air pollution for the public, especially in Malaysia. The API in Malaysia is measured on the basis of the New Ambient Air Quality Standard in accordance with the Pollutant Standard Index (PSI) system that has been standardised by the United States Environmental Protection Agency (USEPA). According to the Department of the Environment Malaysia, the main air pollutants in Malaysia are carbon monoxide $(\mathrm{CO})$, ozone $\left(\mathrm{O}_{3}\right)$, nitrogen dioxide $\left(\mathrm{NO}_{2}\right)$, sulphur dioxide $\left(\mathrm{SO}_{2}\right)$, including particulate matter $(\mathrm{PM})$ with a size of less than $10 \mu \mathrm{m}\left(\mathrm{PM}_{10}\right)$ with the addition of new pollutants in the new standard namely particulate matter with a 
size of less than $2.5 \mu \mathrm{m}\left(\mathrm{PM}_{2.5}\right)$ [1]. In Malaysia, power plants contribute the highest PM emission (36\%) followed by $33 \%, 16 \%$ and $15 \%$ contributions from industry, motor vehicles and other sources, respectively [2].

Particulate matter (PM) can be described as a combination of solid and liquefied particles suspended in the air such as dust, dirt, soot, smoke, and liquid droplets [3]. Exposure to particulate matter especially fine particles such as $\mathrm{PM}_{2.5}$ could cause adverse health effects because the fine particles can travel deeper through the respiratory system than the larger particles [4-7]. The World Health Organization reported that almost $92 \%$ of the world's population lives in

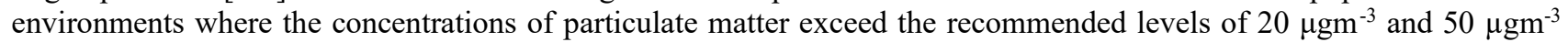
for annual and 24-hour means respectively [8]. The monitoring of air quality is vital as low air quality may have a negative effect on human health as well as on the environment. Therefore, it is significant to control and monitor the particulate matter concentrations so that a safer future can be provided for the next generations.

Several commercial particulate matter sensors devices are available such as E-Sampler Particulate Matter and GRIMM which are used by researchers to monitor the presence of particulates by the principle of light scattering. However, these devices are generally used for research purposes as the cost is expensive [9]. A new trend has emerged whereby researchers use low-cost sensor such as DSM501A (Samyoung Inc.), GP2Y1010AU0F (Sharp Corp.), Shinyei PPD60PV and PPD42NS (Shinyei Inc.) for monitoring particulate matter in the air due to such devices being small in size, lightweight and low-power consumptions [10,11]. Researchers prefer to use the light scattering principle sensor especially PPD42NS (Shinyei Inc.) as it produces real-time data, low-cost as well as user-friendly [12]. Much research has been undertaken regarding the Shinyei PPd42NS sensor due to the lack of available information regarding the sensitivity, accuracy or particulate uptake by the Shinyei sensor. For example, Johnson and co-workers evaluated the low-cost sensor (SHINYEI: models PPD42NS, PPD20V, PPD60PV) in both high and low concentrations of urban environments. The PPD20V and PPD60PV sensors were recommended as suitable for environments from 0 to 200 $\mu \mathrm{gm}^{-3}$ and 0 to $50 \mu \mathrm{gm}^{-3}$. In addition, the PPD42NS sensor showed good correlation with the reference monitor (TSI DustTrak 8533) during a laboratory test with incense smoke [13].

Several studies using the Shinyei PPD42NS have been conducted by researchers to understand low-cost sensor performance in the laboratory as well as in the ambient environment. Austin and co-workers assessed the performance of the Shinyei PPD42NS and determined the sensor response for particulate matter 2.5 [14]. Meanwhile, Kuula et al. (2017) compared the performance of Shinyei PPD42NS and PPD60PV sensors by the laboratory evaluation method [15]. To date, there are barely any studies on a roof-based Shinyei sensor for enhancing the uptake of particulate matter in the sensor. Therefore, the current authors built a new air monitoring prototypes namely original and roofed prototype to monitor air pollutants, especially particles suspended with a diameter of 10 microns $\left(\mathrm{PM}_{10}\right)$ or less in the air. This device will act as an alternative for researchers to replace the use of expensive air monitoring devices because the air monitoring device here is cheaper and can be used to measure the indoor particulate matter as well as for the outdoor applications in the future.

\section{Methodology}

\subsection{Development of the Air Monitoring Prototypes}

New low-cost on-line sensor prototypes were designed by employing an Arduino ${ }^{\mathrm{TM}}$ microcontroller, a dust sensor (Shinyei PPD42NS), as well as a liquid crystal display (LCD) to display the data. Fig. 1(a) depicts a block diagram of the on-line sensor. The prototypes geometry was $200 \mathrm{~mm}$ length, $130 \mathrm{~mm}$ width and $80 \mathrm{~mm}$ height (Fig. $1 \mathrm{~b}$ and c).

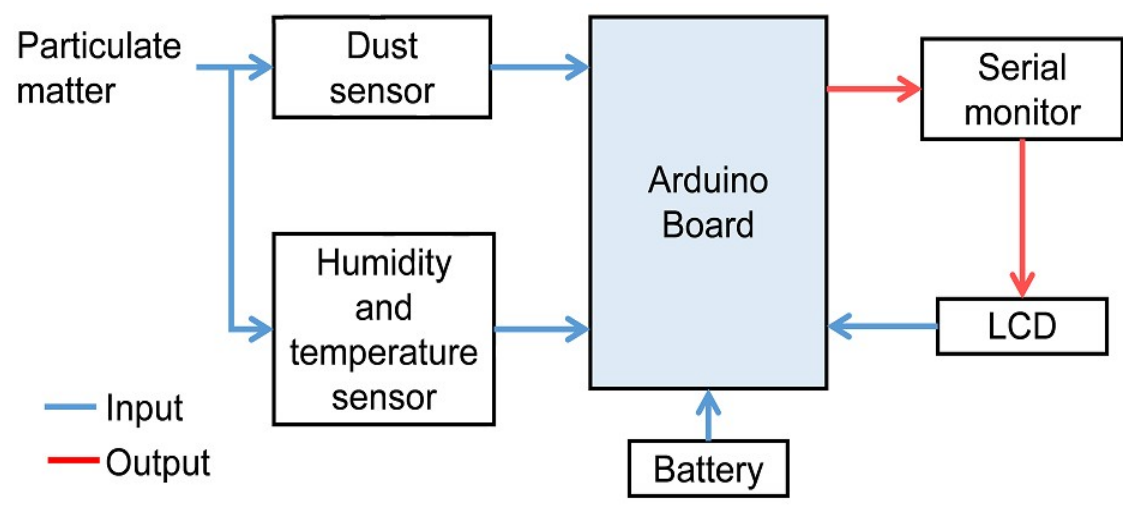


(b)

Back View
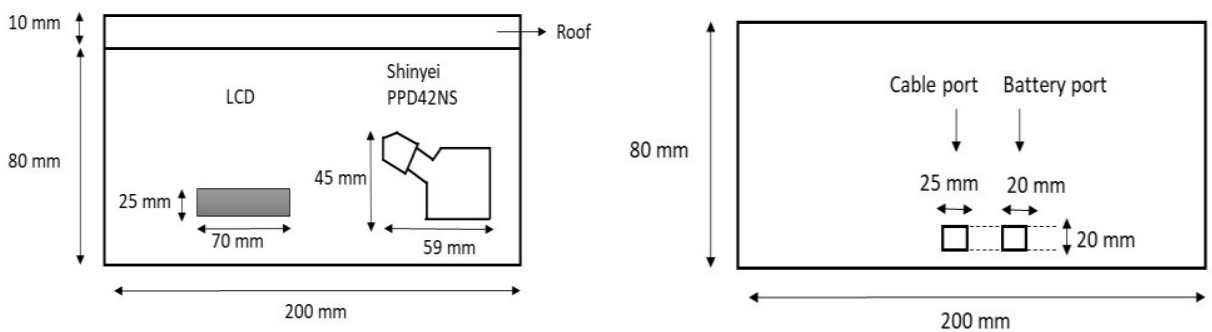

Side View (Left)

Side View (Right)
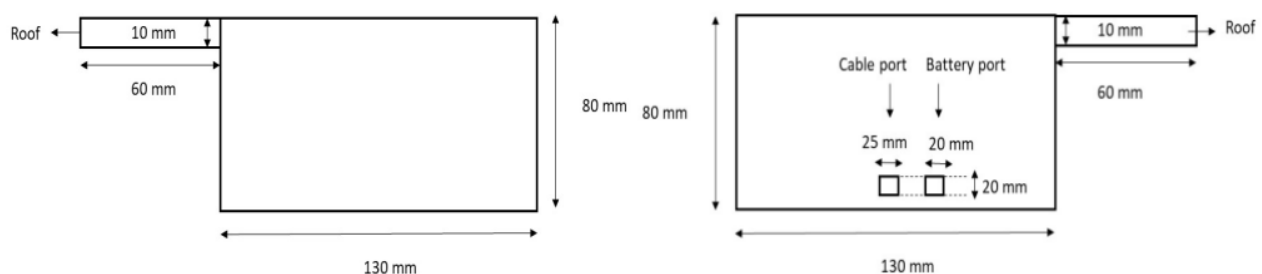

(c)

Back View
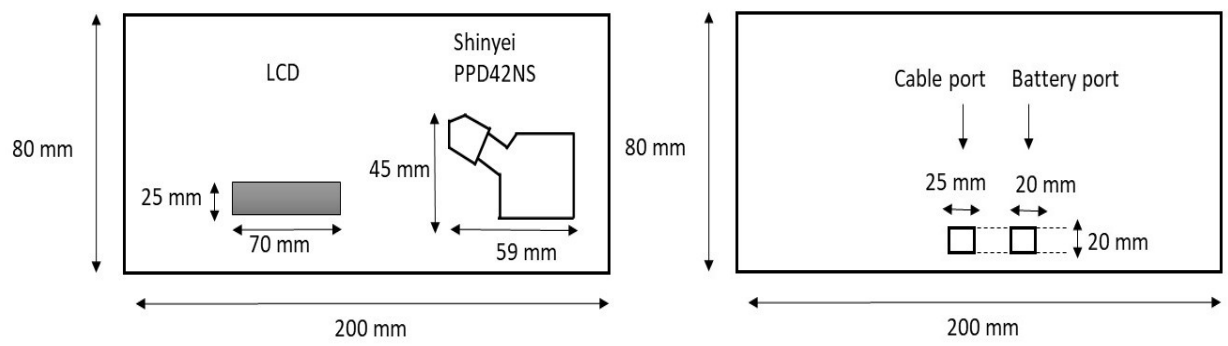

Side View (Left)

Side View (Right)
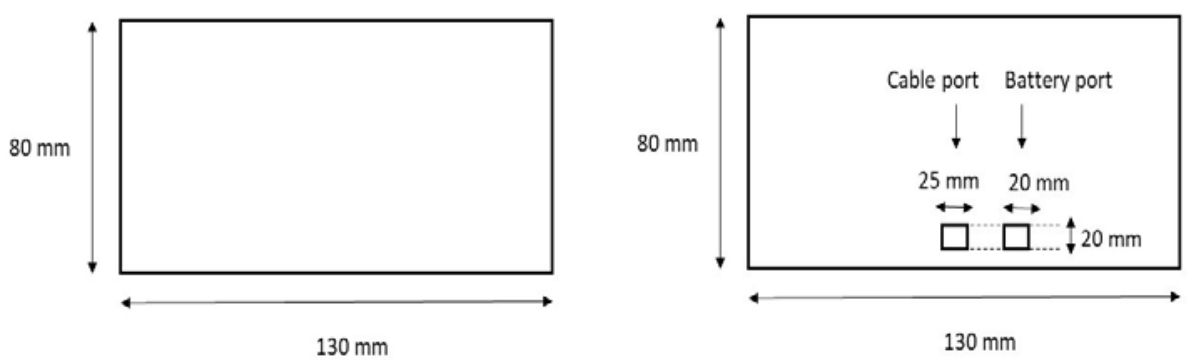

Fig. 1 - (a) Block diagram of the developed air monitoring prototype, (b) 2D Sketch of the roofed prototype and (c) original prototype

\section{Arduino $^{\text {TM }}$}

The prototypes used an open-source hardware platform, Arduino ${ }^{\mathrm{TM}}$ (Arduino UNO R3, Arduino ${ }^{\mathrm{TM}}$, Italy) which generated real-time data and measured the particulate matter in microgram per cubic meter $\left(\mu \mathrm{gm}^{-3}\right)$ [16]. Arduino ${ }^{\mathrm{TM}}$ software uses the programming language $\mathrm{C}++$ to program the Arduino ${ }^{\mathrm{TM}}$ board to read dust concentration specifically $\mathrm{PM}_{10}$. It can be operated by using a $9 \mathrm{~V}$ battery or by connecting the device directly to a USB port. 


\section{Shinyei PPD42NS}

The Shinyei PPD42NS (Shinyei Technology Co., Ltd; Kobe, Japan) is a digital sensor and used to monitor the PM 10 concentrations in this study as the device is easy to obtain as well as not being too expensive. The sensor measure particles using light scattering principles by counting the time that the photodiode sensor detects the particles. The original detection technique is similar to the particle counter technique whereby the pulse output corresponds to the concentrations per unit volume. A schematic diagram of this hardware is depicted in Fig. 2a. The Shinyei sensor consists of a resistor, a light baffle, an infrared light-emitting-diode (LED), a focusing lens, a photodiode detector and electromagnetic shielding. The particles concentration is determined by the signal from the sensors comprising of a low pulse occupancy which is the time that the digital signal is held low [14].

\subsection{Prototypes Validation}

Two design of prototypes were proposed original and roofed prototype. The developed prototypes were analysed using CFD simulation before it was used to measure the $\mathrm{PM}_{10}$ concentrations. It is important to determine the airflow direction on the front surface of the original and roofed prototype so that the particulates will enter the Shinyei sensor during the validation test. Shinyei PPD42NS sensor used in the prototype was evaluated with the same types of sensor to assess the performance and ability of Shinyei PPD42NS in measuring PM $_{10}$ concentrations. Then, the prototypes were tested by monitoring the indoor particulate matter.

\section{Computational Fluid Dynamic (CFD) analysis}

CFD simulation was carried out to assess the velocity profile inside the sensor as well as on the front surface of the sensor with the presence or absence of a roof. The airflow for indoor was assumed to be at $0.3 \mathrm{~ms}^{-1}$ as recommended by ASHARE 2007 for both cases original and with roofed prototype [17]. ANSYS (ANSYS Inc., United States) simulation software is an engineering simulation solution in finite element analysis, computational fluid dynamics and design optimisation. CFD is used for generating solutions for fluid flow with or without solid interaction. The physical properties of fluid flow such as velocity, pressure, temperature, density and viscosity should be considered before generating the CFD analysis. The CFD modelling was designed to solve the fluid flow using Reynolds Average NavierStokes equations. The SIMPLE algorithm was used to integrate the Navier-Stokes equations over a meshed computational domain by converting the integral equation to algebraic equations before solving iteratively [18].

\section{Sensor Evaluation}

A parallel experiment (both Shinyei PPD42NS) was completed in Kuala Lumpur (latitude $3.19^{\circ} \mathrm{N}$, longitude $101.73^{\circ} \mathrm{W}$ ). The data was collected in a closed room for one hour at $1.0 \mathrm{~m}$ from the ground to validate both sensors on the basis of their operating system.

The design of the proposed prototype was optimized by adding a roof over the Shinyei PPD42NS sensor. The curvature of the roof was fixed at a $90^{\circ}$. The effect of adding a roof to the Shinyei sensor was studied by comparing the result of particulate matter detected by the original and roofed prototype. 2D sketches of the proposed prototypes with and without a roof were shown in fig. $1 \mathrm{~b}$ and $1 \mathrm{c}$.

\section{Field Validation}

The performance of the developed original prototype was evaluated by monitoring indoor air particulate matter samples in Kuala Lumpur, Malaysia. The data were collected at hourly intervals at each measurement point [19]. The data collection using Shinyei PPD42NS was collected in parallel with GRIMM produced by Grimm Aerosol Technik $\mathrm{GmbH} \& \mathrm{Co}$. KG, Ainring, Germany as a reference instrument. The indoor measurement point was on a desk (1.0 $\mathrm{m}$ above the ground). The GRIMM device uses the same light scattering principle as Shinyei PPD42NS sensor with different light source and position of a detector. The GRIMM device uses a laser diode while the Shinyei PPD42NS used a resistor as a light source. Position of the detector in GRIMM located at the right angle $\left(90^{\circ}\right)$ while detector in Shinyei sensor positioned in $45^{\circ}$.

\section{Results and Discussion}

\section{Prediction of Airflow Movements}

Before the prototypes were operated to measure the $\mathrm{PM}_{10}$ concentrations in air, Computational Fluid Dynamics (CFD) was used to provide a simulation of the airflow inside the Shinyei sensor as the airflow pattern has a significant impact on the particles concentration distribution. Fig. 2(b) and (c) shows airflow movement with different colour contours indicating the variation in velocity. Colours closer to red represent higher velocities and colours closer to blue represent lower velocities. The velocity of the airflow entering the sensor was assumed to be $0.3 \mathrm{~ms}^{-1}$. Air enters the sensor with a higher velocity from the inlet, circulates and mixes in the middle of the sensor before travelling to the outlet located at the top of the sensor. The circulation movement of the air inside the sensor was also in accordance 
with a study by Beghein et al. (2005) concerning the motion of particles in a room with one inlet in the lower part of the left wall and one outlet in the upper part of the right wall. After a $10 \mathrm{~s}$ injection of particles, there was a small recirculation region in the bottom left and right corners. As the particles were light, they tend to follow the air movement and after $30 \mathrm{~s}$ the particle started to spread in a large recirculation region in the middle of the room [20]. The movement of airflow from the inlet to the outlet was due to the thermally-driven upwind flows generated by the resistor at the bottom of the sensor [21]. The position of the sensor should be considered during the data collection because it has an impact on the airflow created by the air temperature gradient produced by the resistor. Therefore, the current authors took this into account and placed the Shinyei sensor in a vertical position. If the sensor was in a horizontal position and the resistor was on, the temperature at the inlet would be higher compared to the outlet as the hot air from the resistor will rise and leave the sensor through the nearer aperture which is the inlet. It was recommended by Canu et al. (2018) to place the sensor in a vertical position because in such a vertical position the hot air at the bottom of the resistor will rise upward and leave the sensor through the outlet [22].

Another study was undertaken by Zhang and Chen (2006) respect to predicting particle distribution in a room with a different ventilation system, found that the movement of the air from the lower part of the room to the upper part was due to the heat generated by the human body [23]. In addition, the Shinyei sensor was built with black case colour for the maximum absorbance of infrared light from the LED because scattering reflection might disrupt the sensitivity of the Shinyei sensor [24].

(b)

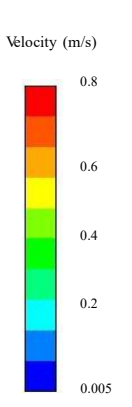

(c
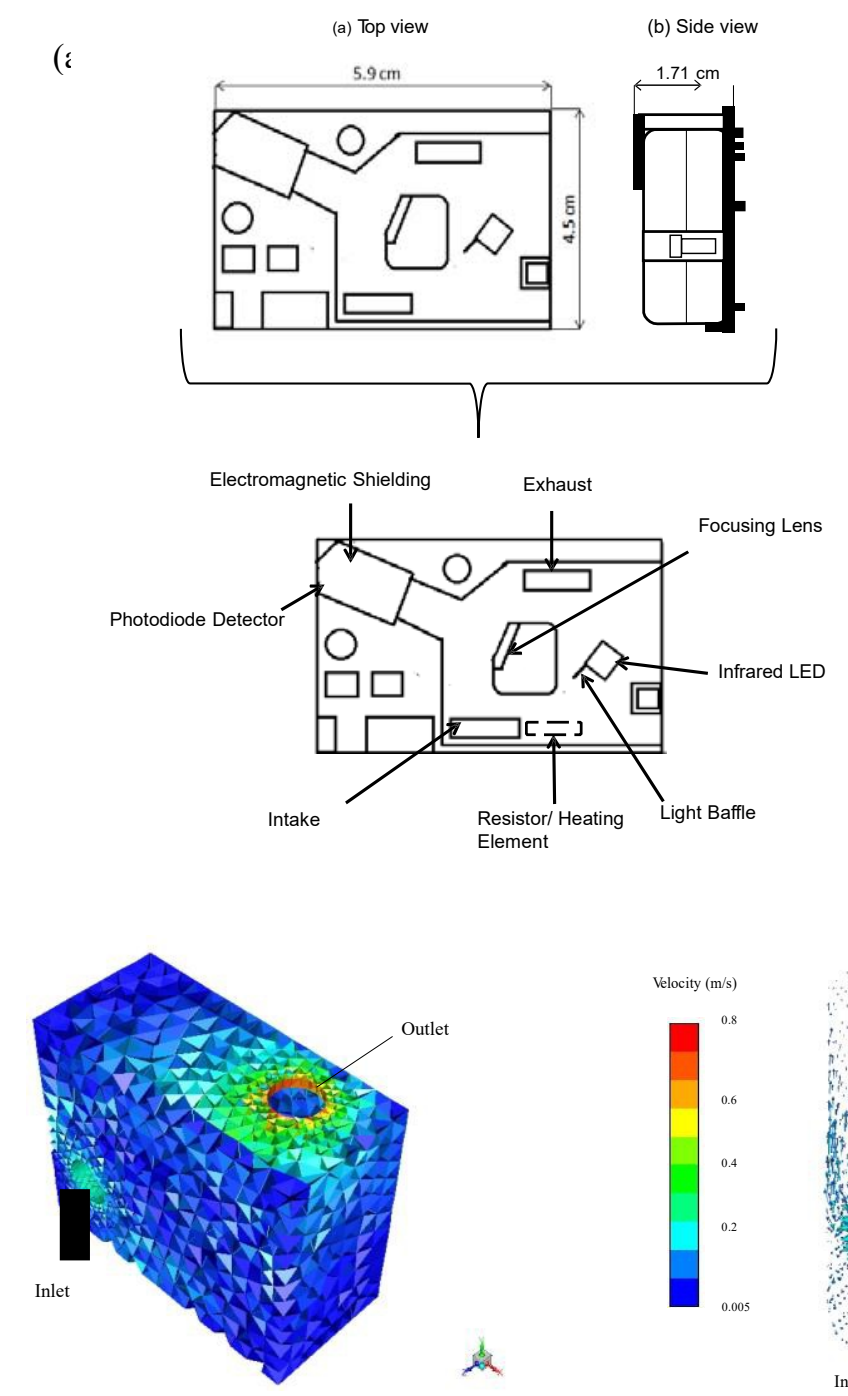

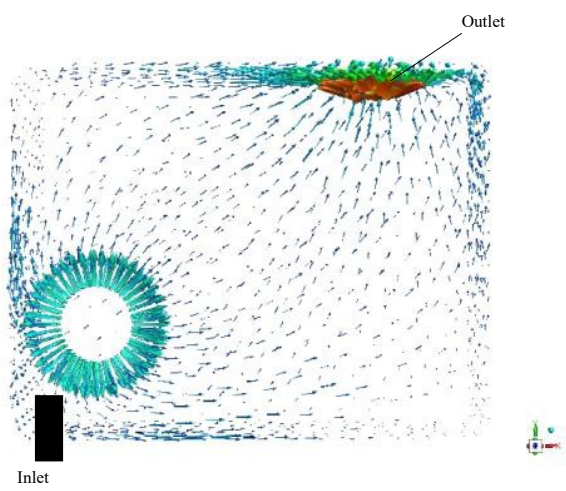

Fig. 2 - (a) Schematic drawings of Shinyei PPD42NS from top view and side view, (b) CFD simulation of Shinyei sensor, (c) Airflow movement inside the Shinyei sensor (PPD42NS) 


\section{Parallel Experiment of Original Prototype}

Fig. 3 compares the $\mathrm{PM}_{10}$ concentrations using the same sensor (Shinyei PPD42NS) as a control sensor. The graph pattern for the sensor used in the experiment (PPD42NS Type 1) showed an approximately similar pattern to the control sensor (PPD42NS Type 2). Within 1 hour of data collection, both sensors detected $\mathrm{PM}_{10}$ in the ambient air thus indicating that the reading of $\mathrm{PM}_{10}$ concentrations detected by the ShinyeiPPD42NS was comparable. However, if different concentrations of $\mathrm{PM}_{10}$ detected by both sensors this might be caused by different exposures of the sensor. PPD42NS Type 1 and PPD42NS Type 2 showed the highest concentrations of $\mathrm{PM}_{10}$ with readings of $1000 \mu \mathrm{gm}^{-3}$ and $1300 \mu \mathrm{gm}^{-3}$ respectively. If the graph pattern from PPD42NS Type 1 showed significant differences from the control sensor, this might be due to the problem of drift in the sensor's response thus causing the sensor not to work properly during deployment. Deposits formed on the lens of the optical sensor led to the sensor drift phenomena. Therefore, it is suggested to clean the lenses, replace the worn sensor (the price is cheap) as well as routinely calibrate the sensor [14].

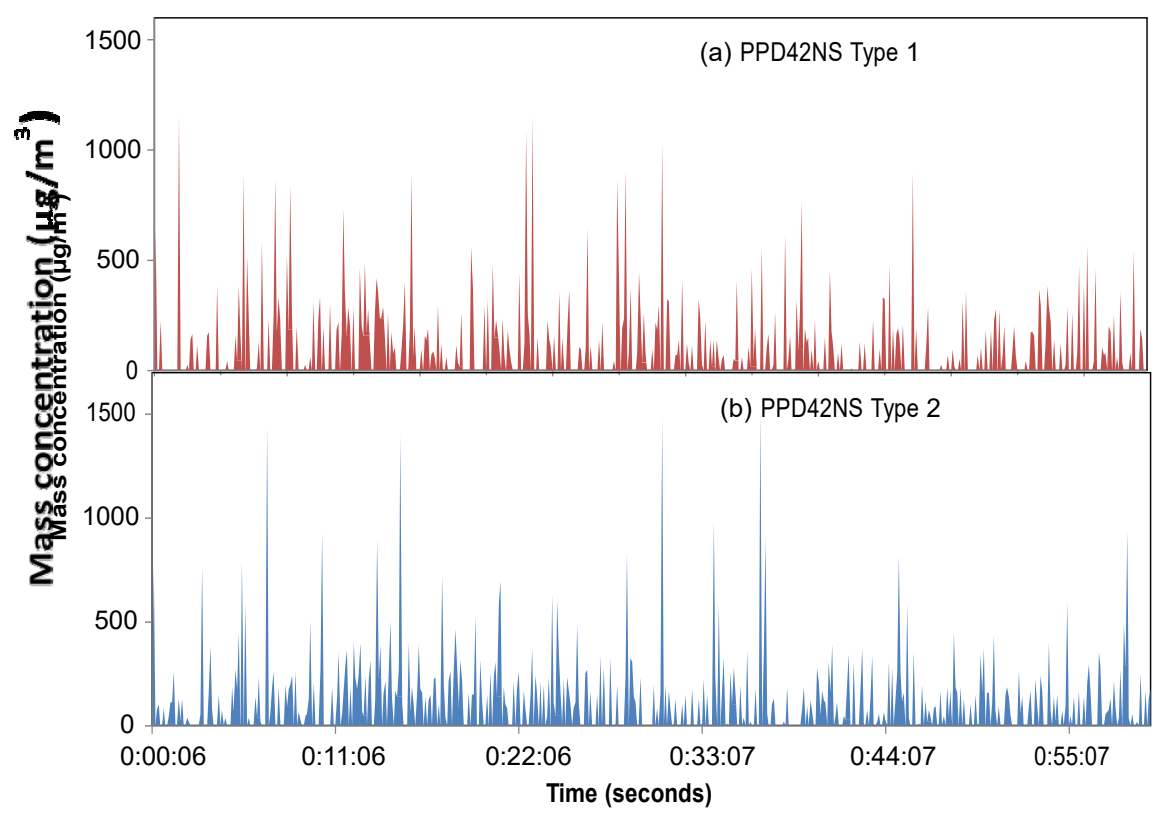

Fig. 3 - Comparison between PPD42NS Type 1 (used in sensor) and Type 2 (control)

\section{Performance of the Original and Roofed Prototypes}

The performances of the original and roofed prototype were compared by measuring the indoor $\mathrm{PM}_{10}$ concentrations. Fig. 4 portrays that in between minutes 10 to 40 no particulate matter was detected by the original prototype. However, some $\mathrm{PM}_{10}$ were detected by the roofed prototype with highest concentrations of $\mathrm{PM}_{10}$ at minutes 15 with a reading of $822 \mu \mathrm{gm}^{-3}$. The addition of a roof makes the prototype more stable and sensitive to detect $\mathrm{PM}_{10}$ in the air, especially for outdoor measurement condition. Other than that, the roof will shield the infrared inside the Shinyei sensor from being overexposed to sunlight which might distract the reading of $\mathrm{PM}_{10}$ concentrations and also increase the stability of the suspended particles. Based on CFD analysis in Fig. 5a, the air velocity under the roof was $0.3 \mathrm{~ms}^{-1}$ which was slightly lower compared to the velocity at the front of the original prototype $\left(0.4 \mathrm{~ms}^{-1}\right)$. As the air velocity under a roof low, more particulates tend to swirl and accumulated before passing through the inlet of the Shinyei box. This result was similar to Chang et al. (2009) who conducted a study on the transport mechanism of particulate matter at open and staggered street canopies (buildings layout). For staggered street canopies, more particles deposition on the building wall compared to the open street canopies due to particles hindered by the buildings [25]. However, a different situation will occur when there is no roof attached to the top of the Shinyei sensor. The absence of a roof will cause the particulates to be freely dispersed and there was a high tendency for the particulates not enter the sensor as displayed in Fig. 5(b), thus leading to a lower detection of PM $_{10}$ concentrations at minutes 10 to 40 in Fig. 4. This shows that the presence of a roof will reduce the exposure of the Shinyei sensor to sunlight and enhances the particle detection of particulates in the air. 


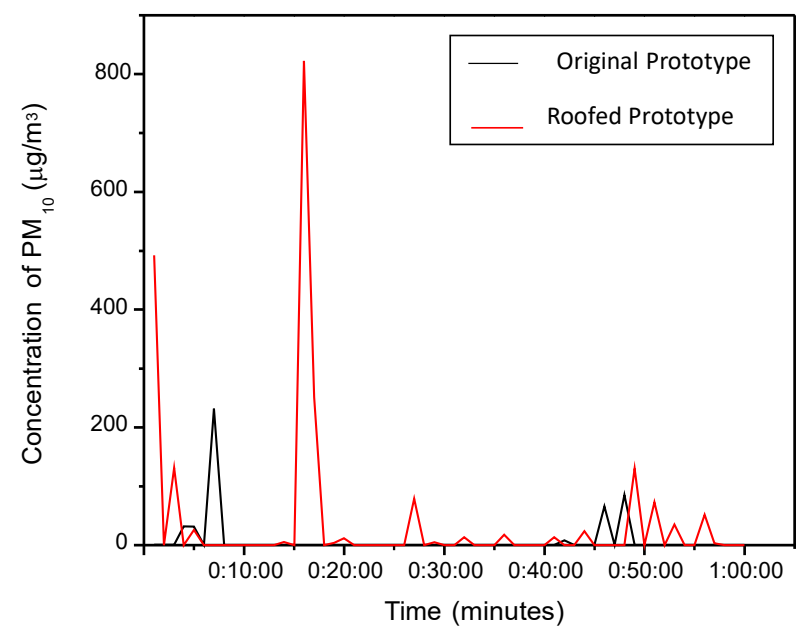

Fig. 4 - The concentration of $\mathrm{PM}_{10}$ detected by roofed and original prototype

(a)

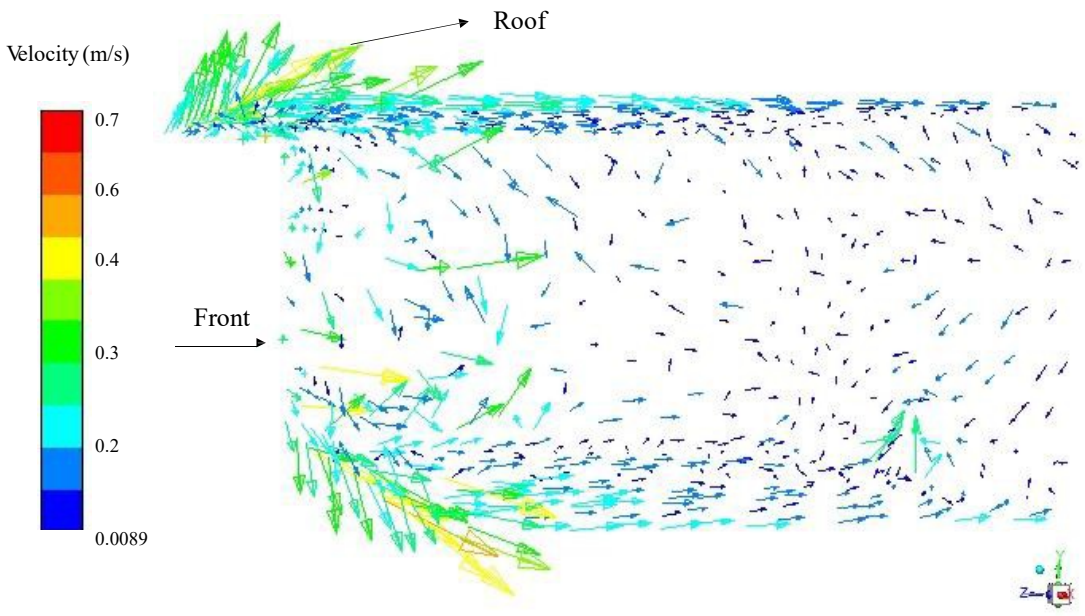

(b)

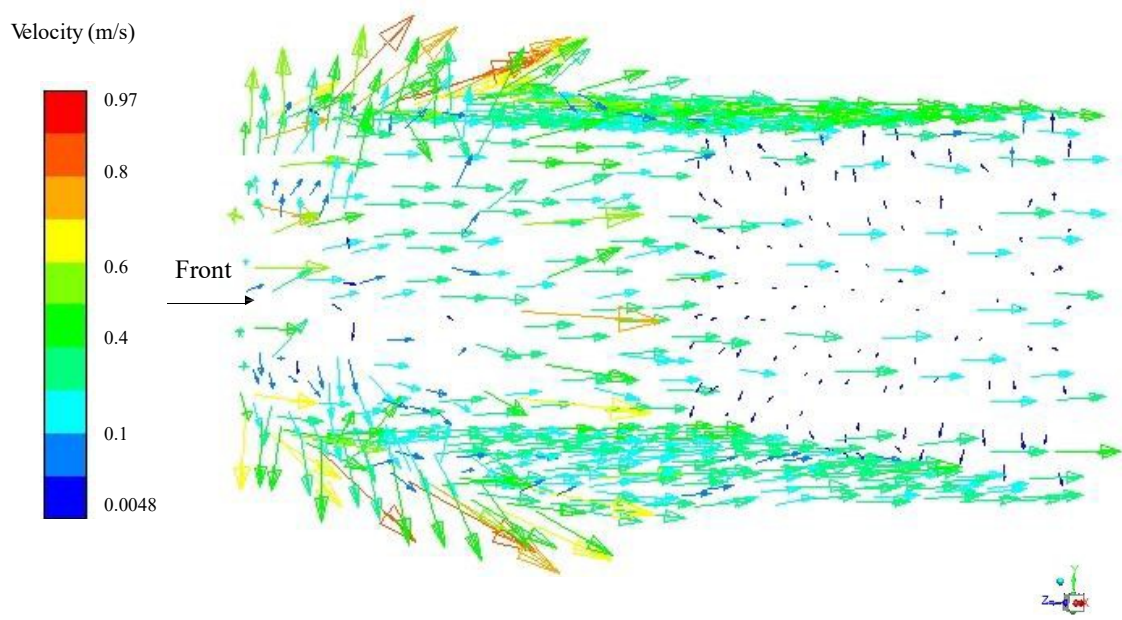

Fig.5 - Airflow movement through (a) roofed prototype and (b) original prototype 


\section{Monitoring Indoor Air Quality}

The original prototype was tested along with the commercially available optical instrument GRIMM as a reference instrument. Fig. 6 portrays a graph of the $\mathrm{PM}_{10}$ mass concentrations detected by both the Shinyei in original prototype and GRIMM sensors against time. Based on Figure 6, the $\mathrm{PM}_{10}$ concentrations measured by the original prototype was higher than those obtained by the GRIMM device due to different conditions and exposure at a specific location. The prototype was placed on a table to increase the accuracy of the sensor for monitoring the ambient air quality because particles suspended on the carpet can contribute to the higher reading of $\mathrm{PM}_{10}$ concentrations. From the graph, the concentrations of $\mathrm{PM}_{10}$ decreased to $62 \%$ and $28 \%$ within the 1 hour of data collection for the original prototype and GRIMM devices respectively. The highest $\mathrm{PM}_{10}$ concentrations were detected in minutes 5 by both Shinyei and

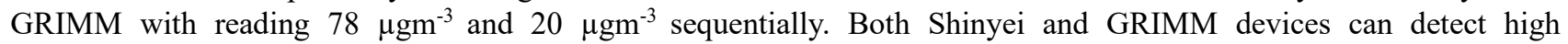
concentrations of $\mathrm{PM}_{10}$ because the size of the particulate matter is large and mostly found at the lower level due to the gravity effect. According to Mei and Gong (2017) smaller particles with sizes from $0.01 \mu \mathrm{m}$ to $1 \mu \mathrm{m}$ were found to be more vulnerable to changes in air stability, while large particles with diameter $2 \mu \mathrm{m}$ to $10 \mu \mathrm{m}$ are more stable in the air due to the dominating role of gravity for heavier particles [26, 27]. Based on the result acquired, the Shinyei PPD42NS can detect higher $\mathrm{PM}_{10}$ concentrations better than the GRIMM device.

The differences in particles delivery cause different readings of $\mathrm{PM}_{10}$ concentrations detected by Shinyei sensor in the original prototype and GRIMM device. The Shinyei sensor depends on the heat generated from the resistor for the movement of particles into the sensor detection area. However, in the GRIMM device a flow-controlled pump was used for the delivery of particles. The presence of a pump in the GRIMM might disturb the movements of particles inside the detection area and causes low scattering of light lead to low concentrations of $\mathrm{PM}_{10}$ detected by GRIMM. As the Shinyei and the GRIMM use the light scattering principles, the sensor output will be affected by the particle properties and sensors design. Examples of particle properties are the refractive index, density, shape, size, the position of a detector and even the particle composition. According to Rai et al. (2017), the magnitude of scattered and absorbed light intensity of the sensor was affected by a diverse particle composition [28]. In addition, the source of light can affect the sensor output. Based on the study by Wang et al. (2015), a light source from a laser diode is more sensitive to smaller size particle. Several factors should be considered during the evaluation of prototype performance in order to get an accurate result [12].

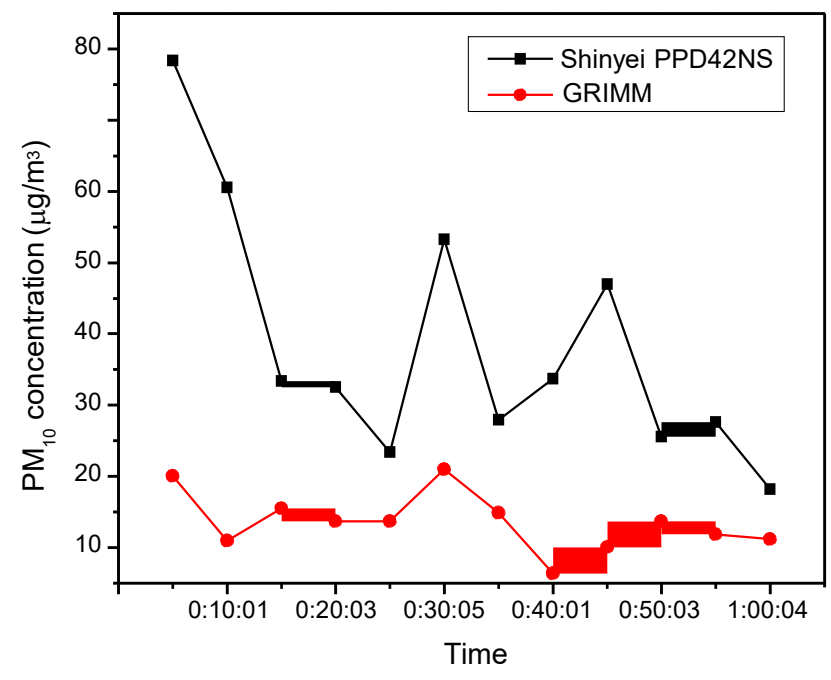

Fig. 6 - Concentration of PM10 detect by Shinyei PPD42NS inside original prototype and GRIMM devices for 1 hour

\section{Conclusion}

New cheaper and portable air monitoring prototypes successfully developed for monitoring particulate matter with the size of less than $10 \mu \mathrm{m}$. The CFD analysis illustrated the air flow inside Shinyei PPD42NS moves in an upward direction from the inlet to the outlet due to the presence of a resistor at the bottom of sensor. A parallel experiment was done using the same sensor and labelled as PPD42NS Type 1 for the sensor used in the air monitoring prototype and PPD42NS Type 2 acted as the control. Both sensors showed the same graph pattern and detected higher concentrations of $\mathrm{PM}_{10}$ up to $1300 \mathrm{\mu gm}^{-3}$ for 1 hour of data collection. Data comparison between the original prototype and roofed prototype showed that roofed prototype detected higher particulate matter concentrations $\left(822 \mu \mathrm{gm}^{-3}\right)$ as the presence of the roof caused the particulates to be suspended under the roof before entering the inlet of the Shinyei sensor. CFD analysis of the roofed prototype illustrated lower velocity of $0.3 \mathrm{~ms}^{-1}$ compared to the original prototype which 
indicated a quite high velocity with a reading of $0.4 \mathrm{~ms}^{-1}$. The functionality of the prototype to detect $\mathrm{PM}_{10}$ concentrations in the air was tested by placing in an indoor environment. Shinyei sensor inside the original prototype detected higher concentrations of $\mathrm{PM}_{10}$ up to $80 \mu \mathrm{gm}^{-3}$ while the commercial GRIMM device only detected $20 \mu \mathrm{gm}^{-3}$. The results showed that a roof attached to the prototype enhances the detection of particulate matter in the air and higher concentrations of $\mathrm{PM}_{10}$ could be detected during data collection. The small size of the prototype makes it portable to be placed anywhere and it is not only for research purposes but also potentially could be used for personal use as a particulate matter monitoring devices. This study will provide a new opportunity for the development of new air monitoring devices with improving the performance of Shinyei based sensor on detecting particulate matter in the air. As the presence of a roof can affect the particulates intake by the Shinyei sensor, different types of material for the roof, size and angle of curvature could be studied in the future to arrive at the optimal performance of the air monitoring devices.

\section{Acknowledgement}

The authors are grateful for the support from Japan International Cooperation (JICA) and funding for this work which was supported by a Potential Academic Staff Grant (PY/2017/01893). The authors also wish to thank Air Resources Ikohza members and Professor Dr. Ezzat Chan in completing this project.

\section{References}

1. Makmom Abdullah, A., Armi Abu Samah, M., and Yee Jun, T. (2012). An overview of the air pollution trend in Klang Valley, Malaysia. Open Environmental Sciences, 6, 13-19.

2. DOE. (2017). Environmental Quality Report 2017. Department of Environment, Ministry of Science, Technology and Environment, Kuala Lumpur, Malaysia

3. Marques, G., Roque Ferreira, C., and Pitarma, R. (2018). A System Based on the Internet of Things for RealTime Particle Monitoring in Buildings. International journal of environmental research public health, 15(4), 821.

4. Hapidin, D.A., Saputra, C., Maulana, D.S., Munir, M.M., and Khairurrijal, K. (2019). Aerosol chamber characterization for commercial particulate matter (PM) sensor evaluation, Aerosol Air Quality Research. 19, 181-194.

5. Mukherjee, A., Stanton, L.G., Graham, A.R., and Roberts, P.T. (2017). Assessing the utility of low-cost particulate matter sensors over a 12-week period in the Cuyama Valley of California. Sensors, 17(8), 1805.

6. Sharma, R. and Balasubramanian, R. (2018). Size-fractionated Particulate Matter in Indoor and Outdoor Environments during the 2015 Haze in Singapore: Potential Human Health Risk Assessment. Aerosol Air Quality Research, 18(4), 904-917.

7. Raffee, A.F., Rahmat, S.N., Hamid, H.A., and Jaffar, M.I. (2019). The behavior of Particulate Matter (PM10) Concentrations at Industrial Sites in Malaysia. International Journal of Integrated Engineering, 11(2).

8. WHO, (2016) Ambient air pollution: A global assessment of exposure and burden of disease. W.H. Organization. Geneva, Switzerland.

9. Mohamed, R., Nizam, N., Al-Gheethi, A., Lajis, A., and Kassim, A. (2016). Particulate Matter Levels in Ambient Air Adjacent to Industrial Area. IOP Conference Series: Materials Science and Engineering, 012056.

10. Zheng, T., Bergin, M.H., Johnson, K.K., Tripathi, S.N., Shirodkar, S., Landis, M.S., Sutaria, R., and Carlson, D.E. (2018). Field evaluation of low-cost particulate matter sensors in high-and low-concentration environments. Atmospheric Measurement Techniques, 11(8), 4823-4846.

11. Dahari, N.A., Wahid, H., Ling, L.P., and Rahim, R.A. (2017). Design of a measurement device for air pollution concentrations using an open-source electronics software and hardware system. International Journal of Integrated Engineering, 9(2).

12. Wang, Y., Li, J., Jing, H., Zhang, Q., Jiang, J., and Biswas, P. (2015). Laboratory evaluation and calibration of three low-cost particle sensors for particulate matter measurement. Aerosol Science Technology, 49(11), 1063-1077.

13. Johnson, K.K., Bergin, M.H., Russell, A.G., and Hagler, G.S. (2018). Field Test of Several Low-Cost Particulate Matter Sensors in High and Low Concentration Urban Environments. Aerosol Air Quality Research, 18, 565-578.

14. Austin, E., Novosselov, I., Seto, E., and Yost, M.G. (2015). Laboratory evaluation of the Shinyei PPD42NS low-cost particulate matter sensor. PloS one, 10(9), e 0137789.

15. Kuula, J., Mäkelä, T., Hillamo, R., and Timonen, H. (2017). Response characterization of an inexpensive aerosol sensor. Sensors, 17(12), 2915.

16. Feng, J., Wei, Y., and Wei, Z. (2018). A PM2. 5 monitoring system for buildings based on Zigbee and Qt technology. 2018 Chinese Control And Decision Conference (CCDC), 1675-1679. 
17. Hassan, Q.H., Ahmed, S.T., and Mahdi, A.a.A. (2014). Numerical Simulation of Air Velocity and Temperature Distribution in an Office Room ventilated by Displacement Ventilation System. International Journal of Scientific \& Engineering Research, 5(4), 32-42.

18. Jurelionis, A. and Isevičius, E. (2008). CFD predictions of indoor air movement induced by cold window surfaces. Journal of Civil Engineering and Management, 14(1), 29-38.

19. Holstius, D.M., Pillarisetti, A., Smith, K., and Seto, E. (2014). Field calibrations of a low-cost aerosol sensor at a regulatory monitoring site in California. Atmospheric Measurement Techniques, 7(4), 1121-1131.

20. Beghein, C., Jiang, Y., and Chen, Q.Y. (2005). Using large eddy simulation to study particle motions in a room. Indoor air, 15(4), 281-290.

21. Liu, D., Zhang, Q., Jiang, J., and Chen, D.-R. (2017). Performance calibration of low-cost and portable particular matter (PM) sensors. Journal of Aerosol Science, 112, 1-10.

22. Canu, M., Galvis, B., Morales, R., Ramírez, O., and Madelin, M. (2018). Understanding the Shinyei PPD24NS low-cost dust sensor. 2018 IEEE International Conference on Environmental Engineering (EE). 1 10 .

23. Zhang, Z. and Chen, Q. (2006). Experimental measurements and numerical simulations of particle transport and distribution in ventilated rooms. Atmospheric environment, 40(18), 3396-3408.

24. Rumantri, K., Khakim, M.Y.N., and Iskandar, I. (2018). Design and Characterization of Low-Cost Sensors for Air Quality Monitoring System. Indonesian Journal of Science Education, 7(3), 347-354.

25. Chang, T.-J., Kao, H.-M., Wu, Y.-T., and Huang, W.-H. (2009). Transport Mechanisms of Coarse, Fine, and Very Fine Particulate Matter in Urban Street Canopies with Different Building Layouts. Journal of the Air \& Waste Management Association, 59(2), 196-206.

26. Zaidi, A.A., Tsuji, T., and Tanaka, T. (2015). Hindered settling velocity \& structure formation during particle settling by direct numerical simulation. Procedia engineering, 102, 1656-1666.

27. Mei, X. and Gong, G. (2017). Influence of indoor air stability on suspended particle dispersion and deposition. Energy Procedia, 105, 4229-4235.

28. Rai, A.C., Kumar, P., Pilla, F., Skouloudis, A.N., Di Sabatino, S., Ratti, C., Yasar, A., and Rickerby, D. (2017). End-user perspective of low-cost sensors for outdoor air pollution monitoring. Science of The Total Environment, 607, 691-705. 